\title{
Dural arteriovenous fistula and spontaneous choroidal detachment: new cause of an old disease
}

\author{
JOHN W. HARBISON, DUPONT GUERRY, AND HERBERT WIESINGER \\ From the Departments of Neurology and Ophthalmology, Medical College of Virginia, USA
}

SUMMARY A case is presented in which bilateral spontaneous choroidal detachments appear to be the direct result of bilateral dural arteriovenous fistula of the cavernous sinus region. Rapid resolution of the clinical signs followed bilateral orbital decompression via the transfrontal approach. Similarities in clinical presentation of both entities are reviewed and a premise for their cause-andeffect relationship elaborated. A literature search for similar unrecognised cases is discussed. The paper suggests that this association may be more frequent than published reports would imply.

Spontaneous choroidal detachment and dural arteriovenous fistulae of the cavernous sinus are uncommon clinical entities. Each produces a relatively characteristic syndrome with a constellation of ocular signs and symptoms. Their occurrence together has been previously reported on only a single occasion (Woillez et al., 1967).

A patient with this rare clinical combination recently provided the opportunity to study extensively their association. The results of this investigation suggest the association may not be as unusual as the current literature would suggest. A plausible basis for the relationship of spontaneous choroidal detachment with dural arteriovenous fistulae in the region of the cavernous sinus is now proposed.

\section{Case history}

A 70-year-old White male professor emeritus of internal medicine noted irritation and a foreign body sensation of both eyes associated with lacrimation, conjunctival injection, and mild lid oedema in October 1973. Before the onset of symptoms he admitted to much stress in his work as well as a minor fall in which he struck the right side of his head without apparent injury. Initial therapy with topical steroids by his private ophthalmologist provided no improvement.

A thorough medical investigation with neurological consultation was undertaken in June 1974. No

Address for reprints: Dr John W. Harbison, Department of Neurology, Box 698, Medical College of Virginia, Richmond, Virginia 23298, USA history of additional neurological, ophthalmological, endocrine, or medical symptoms was elicited. He specifically denied headache, ocular pain, diplopia, visual loss, or cranial bruits. A review of his past medical history revealed hypertensive cardiovascular disease, coronary artery disease with angina pectoris, diverticulosis and diverticulitis, Dupuytren's contractures, and transient ischaemic cerebral vascular disease characterised by transient global amnesia and left hand inco-ordination of infrequent occurrence.

Physical examination showed the visual acuity to be $20 / 20$ OU. Both pupils were noted to be dilated, the right responding poorly to direct light. Ocular motility was normal and there was no ptosis, although mild lid oedema persisted. Hertel exophthalmometry registered $20 \mathrm{~mm}$ OU. Marked dilatation of conjunctival vessels was now present. No cranial or ocular bruits were detected and there was no increase in resistance to retropulsion of the globe. Slit-lamp examination was normal, and applanation tensions were $21 \mathrm{mmHg}$ OU. Retinal changes were characterised funduscopically by mild venous engorgement, small dot haemorrhages, and arteriovenous nicking. No significant findings were recorded on general physical or neurological examination.

Laboratory studies giving normal results at that time included: total and differential blood counts, ESR, urine analysis, BUN, glucose, serum electrolytes, calcium, phosphorus, alkaline phosphatase, LDH, SGOT, cholesterol, bilirubin, total protein and $A / G$ ratio, creatinine, uric acid, serum protein electrophoresis and immunoglobulins, cryoglobulins, tuberculin and histoplasmin skin tests, and 


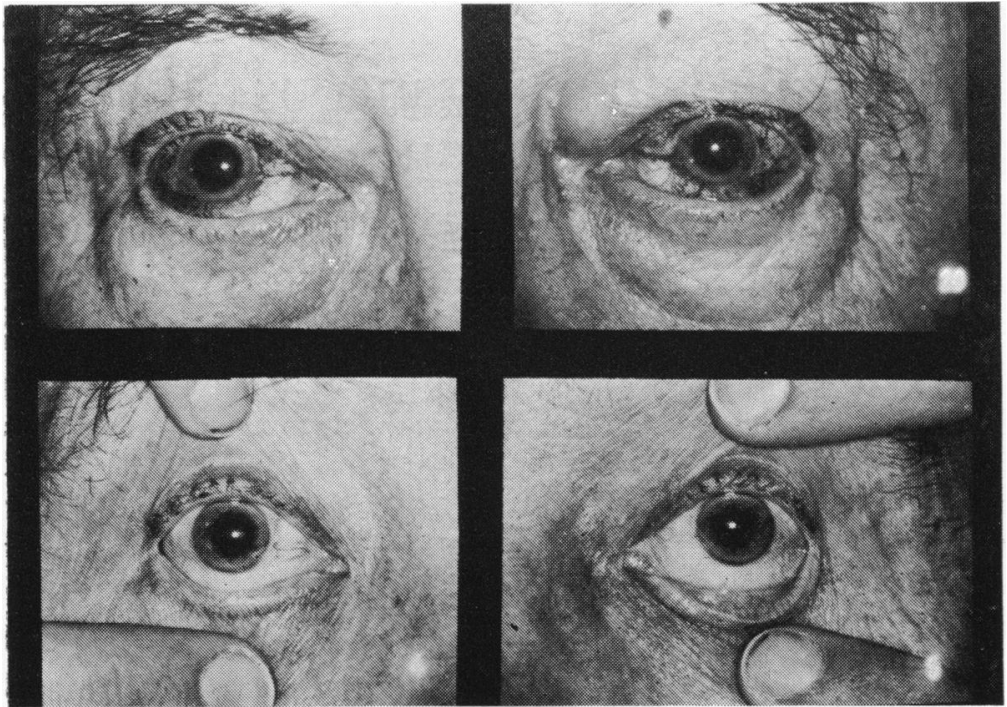

Fig. 1 Top view shows conjunctival vascularity at the time of admission. Bottom view shows resolution of conjunctival vascularity

toxoplasmin serum titres. Chest and skull $x$-rays were normal. The electrocardiogram revealed a right bundle branch block, left anterior hemiblock, occasional ventricular ectopic beats, and left ventricular hypertrophy.

No diagnosis was then established, though a hyperviscosity syndrome was considered.

At 2 subsequent ophthalmic examinations no new diagnositic suggestions were provided. On 2 August 1974 visual acuity OD had dropped to 20/40, and an intraocular mass was noted temporally from 7 to 10 o'clock. A choroidal melanoma was suspected. A second opinion was requested of the authors before proposed enucleation.

Examination on 7 August confirmed the presence of a pigmented mass extending from 7 to 10 o'clock temporally $\mathrm{OD}$. The mass transilluminated. Fluorescein angiography showed only the previously noted vascular changes. A nasal visual field loss was noted. The remainder of the ocular examination was unchanged. In view of this examination the mass was thought to be a choroidal detachment, and the patient was begun on oral prednisone $60 \mathrm{mg}$ daily. By 19 August 1974 the choroidal detachment was more extensive $\mathrm{OD}$, involving both the temporal and nasal segments. A temporal and inferior choroidal detachment was now present OS.

Three days later abrupt proptosis OD, with limitation of motility and ptosis, occurred over a period of 15 minutes. The patient was placed at bed rest, and by 25 August the proptosis, motility defect, and ptosis had resolved.

On 3 September 1974 the patient was admitted to the Neuro-Ophthalmology Service at the Medical
College of Virginia. On admission conjunctival vascular changes (Fig. 1) with mild chemosis and lid oedema were re-affirmed. Visual acuity OD had fallen to light perception. Acuity OS was 20/50, could not be improved, and was associated with a moderate red/green colour perception loss. The pupils were both widely dilated; OD remained unresponsive to light, OS normally responsive. Hertel readings were $23 \mathrm{~mm}$ OD and $24 \mathrm{~mm}$ OS.

Ocular motility was restricted in all fields without ptosis. Funduscopic examination demonstrated previously documented bilateral choroidal detachments. Visual field examination revealed both temporal and nasal defects OS; OD could not be effectively plotted (Fig. 2). General physical and neurological examination was normal. No bruit was heard about the head or neck. The differential diagnosis included endocrine exophthalmos and arteriovenous fistula. A low-flow dural fistula was thought to be more likely than a conventional high-flow carotid-cavernous fistula.

In the early morning of 7 September the patient experienced the onset of severe orbital pain. Examination showed increase in proptosis, with Hertel readings now of $28 \mathrm{~mm}$ OD and $26 \mathrm{~mm}$ OS. There was increased chemosis and lid oedema. Ocular motility was restricted in all fields (Fig. 3). The choroidal detachments were nearly complete, and visual acuity had fallen to bare light perception OU. Intraocular pressure was recorded at $46 \mathrm{mmHg}$ OU with fairly shallow anterior chambers.

The patient was immediately begun on acetazolamide and subjected to selective cerebral angiography. This showed bilateral 'low flow' dural arteriovenous 
Fig. 2 Tangent screen visual field at time of admission
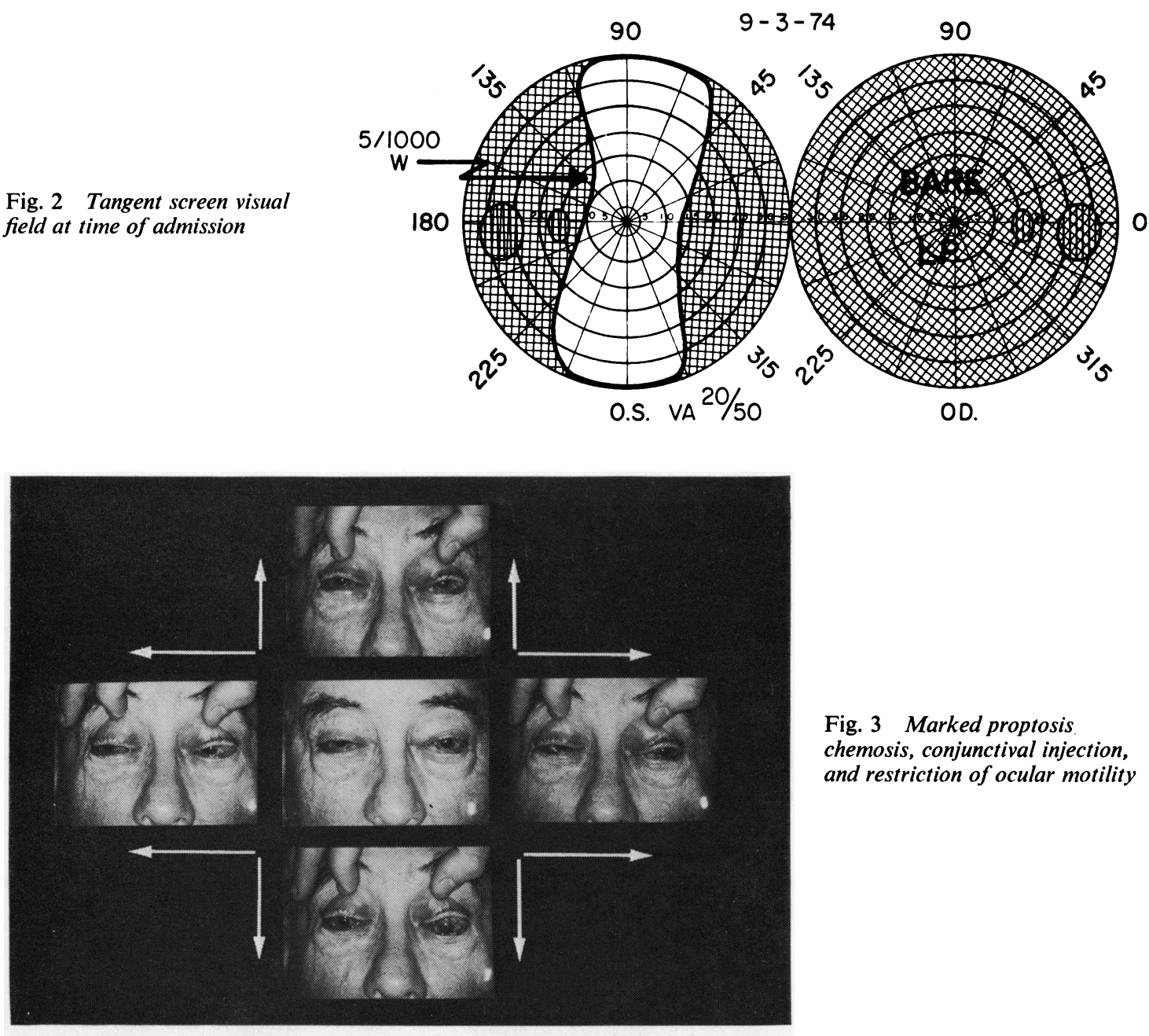

Fig. 3 Marked proptosis chemosis, conjunctival injection, and restriction of ocular motility

fistula draining into the cavernous sinus (Fig. 4). Because of the exacerbation of the orbital signs and symptoms attributed to venous stasis and hypoxia, it was decided to decompress both orbits in an attempt to reverse the course of events and regain vision. Bilateral transfrontal orbital roof decompression was therefore undertaken shortly after angiography.

The immediate postoperative course was uneventful. The patient experienced progressive improvement, and by December 1974 both eyes were quiet and white (Fig. 1). Visual acuity was 20/30 OS and 20/40 OD, and ocular motility full (Fig. 5). The choroidal detachments were largely resolved. At this point it was considered that both fistulae had undergone thrombosis. He has continued an asymptomatic course since then.

\section{Discussion}

The initial clinical description of spontaneous choroidal detachment has been attributed to von Graefe in 1854 (McDonald et al., 1964). Ursin (1965) found 100 reported cases. Small series (McDonald et al., 1964; Preisler, 1965; Rosen and Lyne, 1968; Davis et al., 1973; Scheie and Morse, 1974), as well as single cases (Horay, 1935; Karaske, 1935; Csillag, 1937; Mathews and Moodie, 1955; Lewallen, 1957; McClure, 1967; Woillez et al., 1967; Brockhurst and Lamb, 1973) of spontaneous exudative or serous choroidal detachment continue to be reported, emphasising the infrequency of this clinical entity.

By definition spontaneous choroidal detachment excludes separation of the choroid related to intra- 


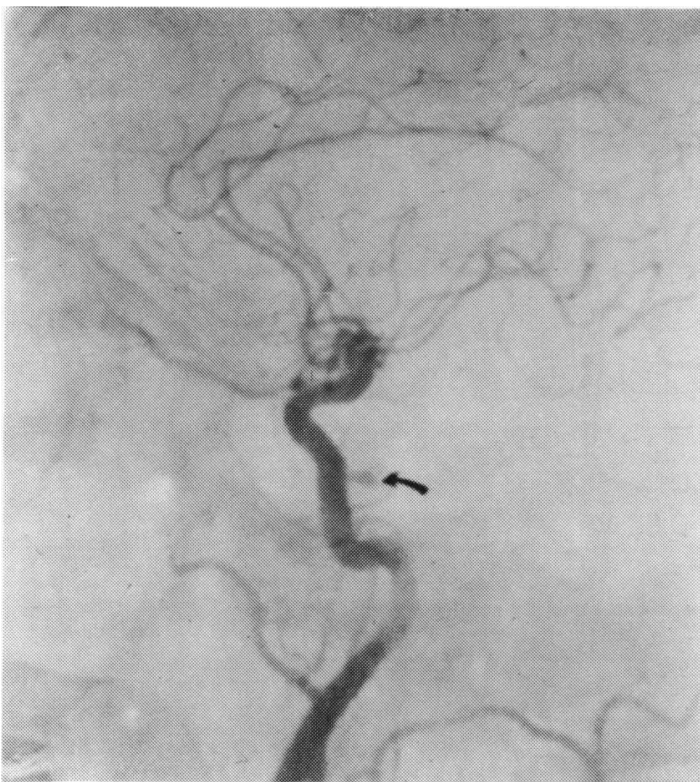

$4 a$

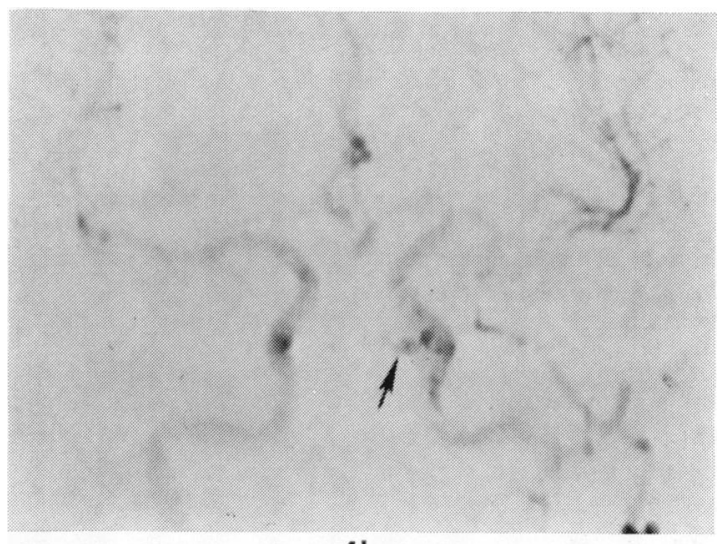

$4 \mathrm{~b}$

Fig. 4a Lateral view of the left common carotid artery injection. There is early filling of the posterior cavernous sinus (curved arrow)

Fig. 4b Frontal view of left common carotid artery injection with manual cross-compression of right carotid artery. Early filling of cavernous sinus is seen medially (arrow)
Fig. 5 Complete resolution postoperatively of proptosis, chemosis, conjunctival injection, and oculomotor restriction

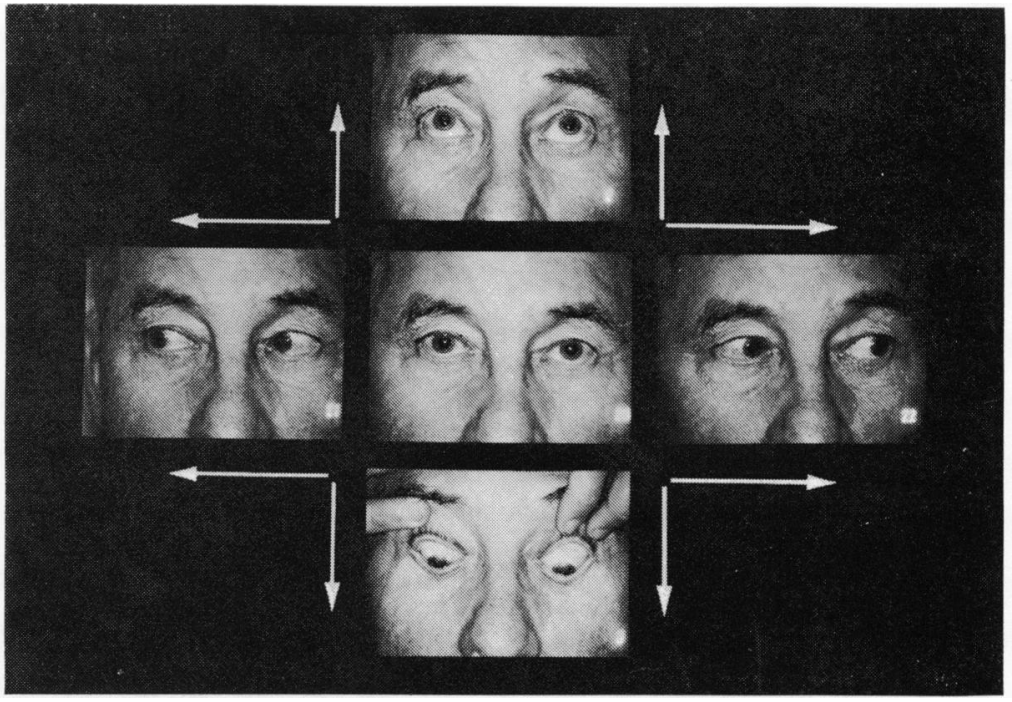

ocular surgery, trauma, obvious focal infection or haemorrhage, and traction effects in a phthisical eye. It has been associated with many local ocular as well as systemic diseases (Schepens and Brockhurst, 1963; Gupta et al., 1965). Common among these has been ocular inflammation: iridocyclitis, tenonitis, and scleritis.

Spontaneous choroidal detachment most commonly presents over the age of 55 , with a predilection for males. Presenting symptoms consist of visual impairment often associated with pain, photophobia, and epiphora. Visual loss of significant degree is commonly associated with shallowness of the anterior chamber, hypotony, retinal venous stasis, and contraction of the visual field. Additional signs included: increased intraocular pressure, proptosis, conjunctival injection, and nonrhegmatogenous retinal detachment. The course is 
often characterised by remission and recurrence of symptoms.

A number of theories have been considered with regard to the aetiology of spontaneous exudative or serous choroidal detachment. Although its cause remains elusive, it is generally accepted that a vascular process producing choroidal congestion is the source of transudation, which results in the choroidal separation (Verhoeff and Waite, 1925; Capper and Leopold, 1956; Lewallen, 1957; Cogan, 1960; Davis et al., 1973; Scheie and Morse, 1974). This concept is experimentally supported by Aaberg's work in the owl monkey (Aaberg, 1974). Most authors agree that many diseases can produce this 'vasculopathy'. This has led Velzebor (1960) to suggest that choroidal detachment should be considered a symptom rather than a separate clinical entity. Perhaps spontaneous choroidal detachment should be considered a secondary clinical entity symptomatic of a primary disease productive of significant alterations of intraocular haemodynamics which include changes in choroidal vascularity capable of inciting transudation.

Carotid-cavernous sinus fistulae with their highflow arteriovenous communication have been easily recognised since Traver's initial description in 1811 . In recent years, with the advent of such major advances in the technology of cerebral angiography as selective catheterisation, magnification, and subtration, a second type of arteriovenous communication has been recognised (Hayes, 1963; Takekawa and Holman, 1965; Mingrino and Moro, 1967; Clemens and Lodin, 1968a; Newton and Hoyt, 1968; Rosenbaum and Schechter, 1969; Newton and Hoyt, 1970; Taniguchi et al., 1971; Houser et al., 1972; Aminoff, 1973; Schlezinger and Schatz, 1973; Katsioris et al., 1974). These dural arteriovenous fistulae are 'low flow' communications between small meningeal branches of both the external and internal carotid arteries and basal venous sinuses, frequently the cavernous sinus or its tributaries. Although the exact pathophysiology of the dural arteriovenous fistula is obscure, current theories include the spontaneous opening of congenital arteriovenous shunts (Clemens and Lodin, 1968b; Aminoff, 1973) and the rupture of thin-walled dural arteries within venous sinuses secondary to minimal trauma (Katsioris et al., 1974) or straining (Taniguchi et al., 1971), with preexistent vascular disease playing an uncertain role (Newton and Hoyt, 1970).

A clinical entity generally distinct from the more florid ocular syndrome of carotid-cavernous fistulae results from the 'low flow' character of these small dural arteriovenous communications. The presentation is commonest over the age of 50 , with an apparent predisposition in women. The most frequent presenting symptoms are headache or orbital pain of unilateral occurrence and often severe nature. Diplopia is usual and an ipsilateral abducens paresis typically the source. Mild nonpulsating proptosis, conjunctival injection, chemosis, and increased intraocular pressure are generally present.

Misdiagnosis early in the course is the rule. Migraine, cluster headaches, endocrine exophthalmos, chronic conjunctivitis, episcleritis, iritis, and orbital tumour have been the most frequent diagnostic errors. The absence of an objective bruit is widely accepted as the major pitfall in diagnosis. A significant number of patients without an objective bruit, however, will provide historical evidence for one at some point in the clinical course. The presentation of the fistula is spontaneous and the course frequently characterised by remission and recurrence of typical signs and symptoms. It may be bilateral but most frequently is unilateral. Some cases have been asymptomatic and incidentally indentified.

If spontaneous choroidal detachments and dural arteriovenous fistulae have more than a chance association, common signs and symptoms should be definable, providing a plausible cause-and-effect relationship. The cohesive elements must then gain support from clinical observations. These criteria appear to be satisfactorily confirmed in the following discussion.

It is clear from the review of cases available in the literature of both spontaneous choroidal detachment and dural arteriovenous fistulae of the cavernous sinus that a group of signs and symptoms are common to selected cases of both clinical entities. These include: mild proptosis, conjunctival injection, orbital pain, moderate increase in intraocular pressure, and evidence of retinal venous stasis. Further, both share a spontaneous mode of onset and a course frequently characterised by remitting and recurrent symptomatology. Finally, both tend to resolve spontaneously after periods measured in weeks to months.

A single case reported by Woillez et al. (1967) provides the only previous documentation of the association of spontaneous choroidal detachment and carotid-cavernous sinus fistulae. Their case differs from ours in that it was a unilateral posttraumatic carotid-cavernous fistula with the choroidal detachment occurring in the ipsilateral eye following a third surgical procedure directed at obliteration of the 'high flow' fistula. Our case more clearly substantiates a significant association, if not cause-and-effect relationship, of spontaneous choroidal detachment and 'low flow' dural arteriovenous fistulae. Another case report of interest in the 
Table 1 Tabulation of documented and possible cases of associated dural arteriovenous fistula and serous choroidal detachm尉

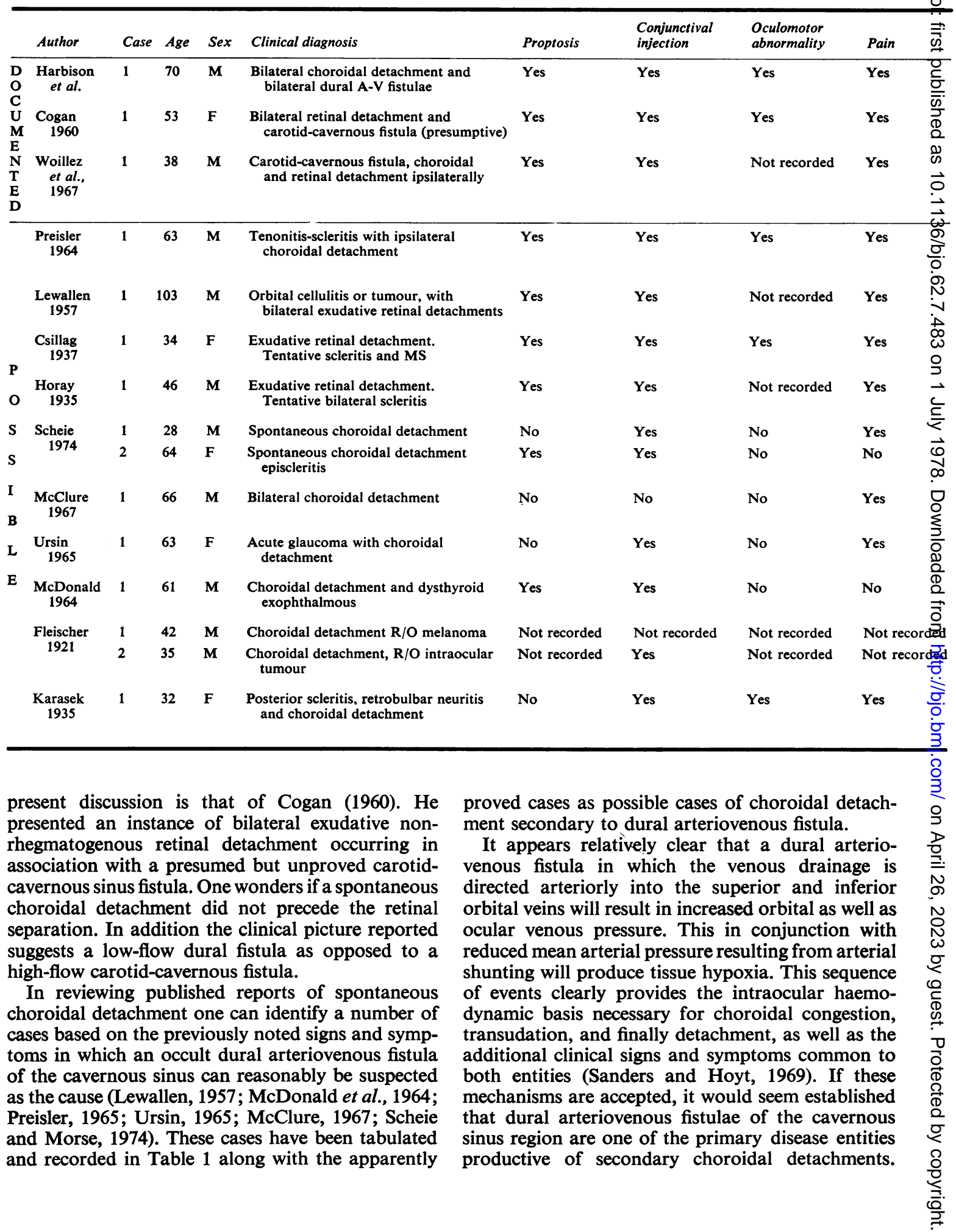


References

\begin{tabular}{|c|c|c|}
\hline $\begin{array}{l}\text { Intraocular } \\
\text { pressure }\end{array}$ & $\begin{array}{l}\text { Retinal } \\
\text { venous stasis }\end{array}$ & Course \\
\hline Increased & Yes & $\begin{array}{l}\text { Bilateral resolution over } 4 \text { months following } \\
\text { transcranial orbital decompression }\end{array}$ \\
\hline Not recorded & $\begin{array}{l}\text { Cloudy } \\
\text { vitreous }\end{array}$ & Spontaneous resolution in 4 months \\
\hline Decreased & Yes & Spontaneous resolution in 3 days \\
\hline Not recorded & No & $\begin{array}{l}\text { Treated with local and systemic steroids, } \\
\text { mydriatic and antibiotics. Resolved in } \\
4 \text { weeks }\end{array}$ \\
\hline Increased & No & $\begin{array}{l}\text { Spontaneous resolution in } 2 \text { weeks. } \\
\text { Treated with antibiotics }\end{array}$ \\
\hline Normal & Yes & $\begin{array}{l}\text { Spontaneous resolution after waxing and } \\
\text { waning course }\end{array}$ \\
\hline Not recorded & Yes & $\begin{array}{l}\text { Spontaneous resolution after waxing and } \\
\text { waning course }\end{array}$ \\
\hline Decreased & No & Waxing and waning course \\
\hline Normal & No & Resolved in 1 month \\
\hline $\begin{array}{l}\uparrow \text { OD } \\
\downarrow \text { OS }\end{array}$ & No & $\begin{array}{l}\text { Treated with steroids. Spontaneous } \\
\text { resolution in } 5 \frac{1}{2} \text { months }\end{array}$ \\
\hline Increased & No & Spontaneous resolution in 2 weeks \\
\hline Increased & No & Eye enucleated for suspected melanoma \\
\hline increased & Yes & Eye enucleated for suspected melanoma \\
\hline increased & Yes & $\begin{array}{l}\text { Waxing and waning course. Patient died } \\
\text { of other disease }\end{array}$ \\
\hline Normal & $\begin{array}{l}\text { Disk and } \\
\text { retinal } \\
\text { oedema }\end{array}$ & $\begin{array}{l}\text { Waxing and waning course with } \\
\text { spontaneous resolution }\end{array}$ \\
\hline
\end{tabular}

Aaberg, T. M. (1974). Experimental choroidal detachments. Modern Problems in Ophthalmology, 12, 167, 172.

Aminoff, J. M. (1973). Vascular anomalies in the intracranial dura mater. Brain, 96, 601-612.

Brockhurst, R. J., and Lam, K. W. (1973). Uveal effusion. II. Report of a case with analysis of subretinal fluid. Archives of Ophthalmology, 90, 399-401.

Capper, S. A., and Leopold, I. H. (1956). Mechanisms of serous choroidal detachment. Archives of Ophthalmology, 55, 101-113.

Clemens, F., and Lodin, H. (1968a). Non-traumatic external carotid-cavernous sinus fistulae. Clinical Radiology, 19, 201-203.

Clemens, F., and Lodin, H. (1968b). Some viewpoints on the venous outflow pathways in cavernous sinus fistulae: angiographic study of 5 traumatic cases. Clinical Radiology 19, 196-200.

Cogan, J. F. (1960). Bilateral retinal detachment following carotid-cavernous fistula. British Journal of Ophthalmology, 44, 185-188.

Csillag, F. (1937). Ein geheilter Fall einter Mit. Netzhautablosung komplizierten Lederhautenzundung. Klinische Monatsblätter für Augenheilkunde, 98, 206-209.

Davis, E. W., Saunders, M. D., and Harry, J. (1973). Annular serous detachment of the choroid. Transactions of the Ophthalmological Societies of the United Kingdom, 93, 145-159.

Gupta, J. S., Chatterjee, A., and Kumar, K. (1965). Massive detachment of the choroid. American Journal of Ophthalmology, 59, 1134-1136.

Hayes, G. J. (1963). External carotid-cavernous sinus fistulas. Journal of Neurosurgery, 20, 692-700.

Horay, G. (1935). Doppleseitiege Netzhautablosung bei Episkleritis mit spontaner heilung, haradasche Erkrangkung?'). Klinische Monatsblätter für Augenheilkunde, 95, 656-659.

Houser, O. W., Baker, H. L., Rhoton, A. L., and Okazaki, H. (1972). Intracranial dural AV malformations. Radiology, 105, 55-64.

Karaske, O. (1935). Neuritis retrobulbaris, Amotio retinae und Abduzensparese als initialsymptom einter scleritis posterior. Klinische Monatsblätter für Augenheilkunde, 95, 645-650.

Katsioris, P., Kirkiakopoulos, K., and Taptas, J. (1974). Carotid-cavernous sinus fistulae and dural arteriovenous shunts. Vascular Surgery, 8, 60-69.

The case presented as well as those identified and suspected in the literature lends clinical support to this contention.

If this premise is accepted, it would seem reasonable to consider selective cerebral angiography in appropriate cases presenting spontaneous choroidal detachments. These cases should exhibit a significant number of those features common to dural arteriovenous fistulae. We would suggest these include: proptosis, conjunctival injection, increased intraocular pressure, pain, and diplopia. If a realistic diagnosis approach to the investigation of spontaneous choroidal detachment is pursued, we may expect the incidence of inciting dural arteriovenous fistulae to be appropriately determined.

Presented to the American Ophthalmological Society, Hot Springs, Virginia, 29 May 1975. ewallen, W. M. (1957). Exudative retinal detachment. American Journal of Ophthalmology, 43, 679-685.

McClure, H. L. (1967). Massive bilateral choroidal detachment occurring in an aphakic patient 6 years and 9 months postoperative. American Journal of Ophthalmology, 63, 295-297.

McDonald, P. R., DeLa Paz, V. J., and Sarin, L. K. (1964). Non-rhegmatogenous retinal separation associated with choroidal detachment. Transactions of the American Ophthalmological Society, 62, 246-247.

Mathews, R. M., and Moodie, A. R. (1955). Recurrent choroidal detachment. British Journal of Ophthalmology, 39, 437-442.

Mingrino, S., and Moro, F. (1967). Fistula between the external carotid artery and cavernous sinus. Journal of Neurosurgery, 27, 157-160.

Newton, T. H., and Hoyt, W. F. (1968). Spontaneous arteriovenous fistula between dural branches of the internal maxillary artery and the posterior cavernous sinus. Radiology, 91, 1147-1150. 
Newton, T. H., and Hoyt, W. F. (1970). Dural arteriovenous shunts in the region of the cavernous sinus. Neuroradiology, 1, 71-81.

Preisler, E. (1965). Spontaneous choroidal detachment. Acta Ophthalmologica, 43, 751-760.

Rosen, E., and Lyne, A. (1968). Uveal effusion. American Journal of Ophthalmology, 65, 509-518.

Rosenbaum, A. E., and Schechter, M. M. (1969). External carotid-cavernous fistulae. Acta Radiologica, 9, 440-444.

Sanders, M. D., and Hoyt, W. F. (1969). Hypoxic ocular sequelae of carotid-cavernous fistulae. British Journal of Ophthalmology, 53, 82-97.

Scheie, H. G., and Morse, P. H. (1974). Shallow anterior chamber as a sign of nonsurgical choroidal detachment. Annals of Ophthalmology, 6, 317-319.

Schepens, C. L., and Brockhurst, R. J. (1963). Uveal effusion. 1. Clinical picture. Archives of Ophthalmology, 70, 189-201.

Schlezinger, N. S., and Schatz, N. J. (1973). External carotid cavernous fistula. Transactions of the American Neurological Association, 98, 159-160.
Takekawa, S. D., and Holman, C. B. (1965). Roentgenographic diagnosis of anomalous communication between the external carotid artery and intracranial veins. American Journal of Roentgenology, Radium Therapy and Nuclear Medicine, 95, 822-825.

Taniguchi, R. M., Goree, J. A., and Odom, G. L. (1971) Spontaneous carotid-cavernous shunts presenting diagnostic problems. Journal of Neurosurgery, 35, 384-391.

Ursin, K. V. (1965). On 'spontaneous' choroid detachment after acute glaucoma in the light of an exceptional case. Acta Ophthalmologica, 43, 751-760.

Velzebor, C. M. J. (1960). Spontaneous choroidal detachment. American Journal of Ophthalmology, 49, 898-903.

Verhoeff, F. H., and Waite, J. H. (1925). Separation of the choroid with report of a spontaneous case. Transactions of the American Ophthalmological Society, 23, 120-139.

Woillez, M., Blervaque, A., and Dufour, D. (1967). Annular arterior detachment of the choroid and retina following a carotid-cavernous fistula. Bulletin des Sociétés d'Ophthalmologie de France, 67, 819-822. 